\title{
La universidad en la reforma educativa española.
}

\author{
Manuel Jesús Garcia Garrido \\ Rector de la Universidad Nacional de Edu. \\ cacion a Distancia.
}

Al agradecerles su amable hospitalidad y la ocasión que me proporcionan para exponer ante Vds. la problemática de la Universidad en la reforma educativa española, quiero plantear unas cuestiones que a todos nos preocupan y ofrecer una experiencia más a tener en cuenta en el panoráma que hoy presentan las Universidades en el mundo.

El tema lo he vivido intensamente como Rector de una de las Universidades tradicionales, la de Santiago de Compostela, y como ponente en el Parlamento español de la Ley General de Educación.

Como en el mundo entero, la Universidad española se encuentra sometida a una intensa revisión; las dificultades se suceden debidas sobre todo a temporales y huracanes politicos y sociales que dificultan y modifican su rumbo. Ante tantos ataques y tantas soluciones improvisadas y de compromiso, lo primeiro que tenemos que preguntarnos es si en una sociedad de masas tecnificada como la actual sigue teniendo sentido la Universidad. En nuestros días ¿pued mantenerse el espíritu cultural y humanístico de las tradicionales Universidades? ¿Salamanca, Santiago, Ox. ford, Cambridge, Coimbra y tantas otras gloriosas Universidades son sólo reliquias de un pasado o les espera un futuro igualmente glorioso trás esta etapa de incertidumbre? El Reformismo a ultranza que hoy nos invade y la movilidad social ha llegado al extremo de combatir el pasado por ser histórico y a una burda imitación que todo lo moderno entraña.

En la actuación de una reforma a fondo de la Universidad actual, debemos preguntarnos $\dot{i}$ qué va quedar de la Institución universitaria y cómo va a ser la del futuro? Es indudable que tan peligroso sería un 
inmovilismo a ultranza en mantener unas estructuras desfasadas como un reformismo que haga tabla rasa de todos los valores tradicionales en aras de modelos importados y nuevos órganos que transplantados a un cuerpo social menos rico y dotado conduce inevitablemente al rechazo y a la muerte. Recientemente, Jackson ha afirmado que la enseñanza superior implica el asentimiento a una serie de valores educativos y un empeño por lograr un tipo de educación que sea estrictamente superior. Existen unas formas superiores de vida intelectual y cultural y estas son el sujeto de la enseñanza superior. Expresa esta denominación los más profundos y significativos tipos de experiencia humana a los que sólo puede llegar-se elevando la educación a un nuevo plano y no prolongando simplesmente el proceso educativo. En un periodo de rápida innovación y expansión institucional existen indudablemente dificultades en señalar y en acotar los valores educativos. Sin embargo, la enseñanza superior todavía no ha sucumbido a la metáfora industrial. Afortunadamente los professores universitarios no tienen todavia consciencia de pertenecer a la clase de comunidad universitaria que los sociólogos están empeñados en describirnos. En general, sus preocupaciones siguen estando ensus respectiva ramas del saber y en las Instituciones donde está definida la educación. Por ello se ha podido afirmar que el espíritu de selecta educación de Oxford y Cambridge no ha pasado a la historia, sigue siendo necesario al país y el país le viene reconociendo su valor a través de las crecientes subvenciones y contratos de investigación que le concede.

En este orden de ideas podemos decir que la Universidad es la expresión cultural perfectiva de la Sociedad; si va a ser el reflejo pasivo de la Sociedad la Universidad ha dimitido de su mision. La Universidad es por esencia inquietante. Cada país tiene que ser lo que la Universidad le enseña a ser, siempre que la Universidad responda a las auténticas exigencias de la Sociedad.

Para tratar de cuales deber ser las nuevas estructuras de una futura y más perfeccionada Universidad debemos preguntarnos, ante todo, que exige hoy a la Universidad la Sociedad. Dejando aparte los propósitos de los focos sociales que pretendem servirse de las Universidades con finalidades políticas, la sociedad actual pretende, como afirma e informa Robing, que la situación docente cumpla las siguientes misiones: 1) Formación científica completa en las distintas disciplinas y especialidades; 2) capacitación y orentación profesional, que permita a los graduados incorporarse inmediatamente a las tareas sociales; 3 ) iniciación y apren- 
dizaje de los métodos y técnicas de investigación, sin descuidar estar en vanguardia entre la investigación, y las diversas ciencias; 4) promover el desarrollo científico y cultural de la región mediante la aplicación de las técnicas y enseñanzas más avanzadas; 5) además de suscitar en los alumnos los hábitos de reflexión y estudio, el completar su formación humana con los valores intelectuales y morales necesarios para su incorporación a la Sociedad.

Ante tantas y tan complejas exigencias no es de extrañar que la Universidad en nuestros días, desbordada por masas cada vez mayores de estudiantes y dificultada en su misión con problemas de orden pública y con una insuficiencia de medios económicos, no haya sabido encontrar su propio camino y haya visto sometida a un proceso continuo de críticas e incluso de intentos de destrucción y abolición total.

Un conocido autor americano, Perkins, sostiene que una Universidad moderna debe tener tres misiones principales: la adquisición de conocimientos, que es la misión propia de la invetigación, la transmisión del conocimiento, objeto de la enseñanza y la aplicación del conocimiento que es la misión del servicio público.

Mientras que las dos primeras misiones de investigación y enseñanza han sido funciones primordiales de las Universidades Europeas tradicionales, la aplicación del conocimiento es la meta principal de la moderna Universidad americana que desde Franklin y Jefferson, ha reclamado como principal responsabilidad de los universitarios el realizar estudios prácticos para la nueva era.

Un motivo de las dificultades universitarias en nuestro momento histórico reside en la creciente masificación universitaria que amenaza con romper todas las barreras y estructuras de nuestra Institución. Desde 1962 se ha producido en España un aumento vertiginoso del alumnado. La cifra se ha multiplicado en la actualidad por 2'5. El ritmo anual mínino de crecimento puede cifrarse entre los cuarenta o cincuenta mil alumnos. En 1967 el número total de universitarios españoles era de 125.000 ; en 1972 fue de 201.000 y para 1.975 las predicciones son de un número entre 300 a 400 mil alumnos universitarios. En la actualidad 90.000 alumnos cursan el Año de Orientación Universitaria y son candidatos en el curso próximo a ingressar en la Universidad. Para atender a este continuo crecimento se crearon desde 1968: 9 Universidades más, otras 2 Universidades privadas y 20 Colegios Universitarios. 
II. - Las recientes tendencias hacia la autonomía y hacia la participación y la lucha contra el centralismo universitario no es un fenómeno característico de nuestros tiempos, sino que se repite en diversas etapas de la Historia contemporánea española.

La lucha entre centralismo y autonomía es una constante histórica en la vida de la Universidad. Digo autonomía universitaria constituida en gremios o asociaciones, en corporaciones privadas de maestros que atendían a un número de escolares agrupados en los antiguos estudios de las cuatro Facultades tradicionales como eran las Artes, las Leyes, la Medicina y la Teología. La historia presenta etapas sucesivas de predominio de centralimos y de la autonomía. En el Plan de Estudios de 1845 y en la Ley Goyanes la centralización se presentaba como una solución benéfica frente a la anarquía de los regímenes preferentes. Se implanta en esta Ley el monopolio estatal, concibiéndose la educación en su economía y en su concepción administrativa como una pirámide de tres pisos. Se declara que la educación Primaria es competencia de los Ayuntamien. tos, la Media o Secundaria de las provincias y la Enseñanza Superior es competencia del Estado. Para esta centralización se utilizan instrumentos como son el hacer un cuerpo único de funcionarios catedráticos y la preminencia de Madrid que llega a ser la unica Universidad que puede dar el grado de Doctor así como la distribución en distritos universitarios.

La centralización va a estar vigente hasta 1968. El plan de Ruiz Zorrilla es una voz que se levanta contra la centralización, pero se trata de una mera proclama de protesta El Decreto de 1865 de Pidal y Mon constituye una etapa fundamental hacia la autonomía, el preámbulo afirma: afortunadamente va recibiendo entre nosotros progresivo desarrollo el saludable principio de que la enseñanza no debe constituir un monopolio del Estado, si un mero servicio administrativo, sino una función social a la cual han de cooperar todas las fuerzas e iniciativas de la vida social, compartiendo con el gobierno las glorias y responsabilidades de esta obra fecunda de regeneración, en cuyo seno se define la suerte de las futuras generaciones.

Pero el reconocimiento de la autonomía se da en el plan de César Silio de 1919 que pasa a reconocer a las Universidades y a las Facultades como personas jurídicas y que considera que cada Universidad debe tener un estatuto singular. Tal estatuto, dice la exposición de motivos, 
una vez aprobado por el Gobierno será la ley interna que defina, delimite y regule sus derechos y su actuación. El Estado dispone el núcleo fundamental de enseñanzas que hay de contener los planes de estudio en las distintas Facultades, pero deja a la vez a cada Universidad en libertad para completar esas enseñanzas y para organizarlas. En este plan se contiene una separación entre la función docente y la función examinadora que habilita para la profesión; la Universidad examina sólo por la ciencia adquirida y los Tribunales del Estado examinan pará la habilitación profesional. Este plan de César Silió de 1919, encontró una gran resistencia, precisamente, entre los universitarios que más clamaban por la autonomía. La reforma fue muy poco duradera, los estatutos aprobados en 1951 fueron truncados un año más tarde abriéndose un nuevo periodo de proceso centralizador.

En nuestra história más reciente, la Ley de 1943 que afirmaba en su preámbulo que nuestra Universidad nació para servir la misión de transmitir el saber, mediante la enseñanza considerando como misiones primordiales la enseñanza, la preparación profesional, la investigación científica, la completa formación que a juventud universitaria y la difusión de la cultura y la ciencia española. La Ley de 1943 dada por unas circunstancias históricas determinadas, a las que indudablemente sirvió, haquedado anticuada después de más de 25 años, pese a los retoques legislativos que han venido surgiendo. Así como centralismo universitário supuso en su momento un adelanto respecto a la proliferación y escasa eficacia de las Universidades locales y regionales, quien se considera como una rémora, la estructura universitaria rígida do la Ley del 43, ha quedado superada por los nuevos métodos de la educación de masas y la acuciante demanda social de las nuevas profesiones a las que no puedem responder la rígida estructuración de las siete Facultades tradicionales que la Ley imponía..

III. - Para compreender la nueva estructura de la Universidad española nacida de la Ley de 4 de agosto de 1970, es necesario encuadrarla en el ámbito más general de la reforma educativa española.

La reforma parte del análisis y crítica del sistema anterior, regido por el esquema ya centenario de la Ley Moyano de 1857 Este régimen respondía a una estructura socio-económica preindustrial, en la que apenas apuntaban algunos intentos aislados de industrialización. Era un sis- 
tema educativo para una sociedad estática que ha quedado ampliamente superada por la evolución de la sociedad española. Las reformas parciales han permitido satisfacer en medida creciente la demanda social de la educación, pero se ha ido a la zaga de la presión social. Los problemas educativos que tenía planteados el país requerían una reforma, amplia, profunda, previsora de las necesidades nuevas y no medidas tangenciales y apresuradas .

La reforma se preparó en febrero de 1969, con la publicación del Libro Blanco que fue presentado a las Cortes y sometido a un amplio debate nacional. Para las observaciones formuladas se tuvieron en cuenta los trabajos de elaboración del Proyecto de Ley de Educación y financiamento de la reforma educativa que aprobado por el Gobierno en 1967, fue presentado a las Cortes en 1970 y discutido por éstas durante más de 6 meses hasta conseguir su definitiva aprobación el 4 de agosto de 1970 .

Los principios más importantes que inspiraban la reforma fueron recogidos en la Ley General de Educación y pueden sintetizarse así:

$\left.1^{\circ}\right)$ Las finalidades son conseguir la formación humana integral, el desarrollo armónico de la personalidad y na preparación para el ejercicio responsable de la libertad, la integración y promoción social y el fomento del espíritu de convivencia.

2. ${ }^{\circ}$ El reconocimiento del derecho a todos los españoles y el correlativo deber del Estado a recibir una educación general y una formación profesional que les capacite para el desempeño de una tarea útil para la sociedad y para ellos mismos.

3. ${ }^{\circ}$ El estímulo y la protección de la Ley en la inicitiva de la sociedad reconociendo y tutelando el derecho de las personas y ciudades a crear y sostener centros de enseñanza reconociendo su autonomia y prestándoles ayuda económica a la función social que desarrolle.

4..$^{\circ}$ Reconociéndole la unidad del processo educativo que supone el facilitar las interrelaciones entre los distintos núcleos y las readaptaciones vocacionales en cualquier edad al considerar la educación como un proceso permanente que dura tanto como la vida del hombre. 
5. ) La renovación de los métodos educativos con la incorporación de las técnicas de la enseñanza activa e individualizada y de la evaluación continuada referida no sólo a los alumnos sino también a los professores y a los centros.

Entre los objetivos que se proponía la Ley son de especial relieve: hacer partícipe de la educación a toda la población española; completar la educación general con una preparación fecunda de individuo y del trabajo, ofrecer a todos la igualdad de oportunidades educativas sin más limitaciones que la de capacidad para el estudio; establecer un sistema educativo que se caracterice por su unidad, flexibilidad e interrelaciones, al tiempo que se facilite una amplia gama de posibilidades de educación permanente y una estrecha relación con las necesidades que plantea la dinámica de la evolución económica y social del país. Se trata en última instancia de construir un sistema educativo permanente, no concebido como criba selectiva de los alumnos sino capaz de desarrollar hasta el máximo la capacidad de todos y cada uno de los españoles.

Es de especial interés poner de relieve que a continuación de cada uno de los niveles educativos se dá una posibilidad de una imediata formación profesional. Así después de la Educación General Básica se consigue una educación profesional de primer grado; después del Bachillerato unificado y polivalente se dá acceso a la formación profesional de segundo grado; y después del primero de los ciclos en que está dividida la educación universitaria y que tiene una duración de tres años, se dá acceso a una formación profesional de tercer grado que posibilita a la inmediata incorporación a las tareas sociales.

La Ley se fijaba un plazo de 10 años para su aplicación y puede decirse que en el tercer año las dificultades y la complejidad de las soluciones han ido aumentando ao mismo tiempo que la resistencia por parte de algún sector del profesorado y de la sociedad se ha ido haciendo cada vez más fuerte y combativa. Al mismo tiempo el desarrollo legislativo de la Ley se va implantando con cierto ritmo pese a las resitencias y a las frustaciones que indudablemente toda reforma educativa trae consigo.

IV. - Los primeros años de la reforma universitaria tras de la aprobación de la Ley General de Educación se han dedicado a la redacción y aplicación de los Estatutos provisionales redactados por las Jun- 
tas de Gobierno de las Universidades, tras de los cuales se procederá a la redacción de los Estatutos definitivos con una participación de todos los estamentos docentes y discentes de la Universidad.

Según la nueva Ley de Educación Universitaria tiene por finalidad completar la formación integral de la juventud, preparar a los profesionales que requiere el país y atender aa funcionamiento en beneficio de las mismas. Son también objetivos de la Universidad el fomento del progreso cultural y del desarrollo de la investigación científica así como el prefeccionamiento del sistema educativo nacional. La educación universitária cursada en Facultades y Escuelas Técnicas Superiores, abarca un primer ciclo dedicado al estudio de disciplinas básicas con una duración de tres años; un segundo ciclo de especialización, con una duración de dos años y un tercer ciclo de especialización concreta y preparación para la docencia que dará derecho al título de Doctor. La educación universitaria se cursa además en Escuelas Universitarias y en Colegios adscritos, repartidos por toda a geográfia peninsular, que contarán con un solo ciclo, con una duración normal de tres años, cada uno de estos ciclos da derecho a un título profesional de diplomado, licenciado y doctor.

Entre las novedades más importantes que se instauran con la nueva autonomía, entendido en un triple plano, académico, administrativo y financiero, se encuentran: la institución de la gerencia que encargada de de la gestión económico-administrativa, descargará considerablemente a las autoridades académicas del peso de los asuntos económicos y burocráticos; la institución del Patronato como órgano de conexion entre la Universidad y la Sociedad que canalizará las aspiraciones de ésta y al mismo tiempo ejercerá un saludable control sobre la hacienda de la Unversidad, recaudando toda clase de bienes y donaciones para que la Universidad pueda cumprir sus objetivos. Se estructura la selección y el nombramiento de las autoridades académicas con amplia participación de todos los elementos que componen el cuerpo universitário.

El Patronato se configura como el órgano de unión entre la Sociedad y la Universidad: "La Sociedad colabora con la Universidad prestando el apoyo necesario para la realización de sus cometidos y planteándole sus proprias exigencias"

Aparte de la creación de los Departamentos, como unidades de docencia, en sustitución de las antigas Cátedras, de los Institutos como 
unidade de investigación y de una administración universitaria más flexible y moderna, tiene importancia la creación en todas las Universidades de Institutos de Ciencias de la Educación, con función de asesoramiento en las modernas técnicas pedagógicas y de formación del profesorado de los distintos niveles.

Aunque todavía sea pronto para hacer um balance de los resultados de la reforma universitaria española, se pueden apreciar síntomas de resistencias al cambio y de dificultades en la realización, debido sobre todo a factores ideológicos y sociales que en la Universidad germinan y se desarrollan. Los Estatutos universitarios han debido ser suspendidos en algunas universidades masificadas; las dificultades de cientos de alumnos son crecientes y los cambios se imponen con lentitud.

Se declara que el objetivo principal que debe buscar o debe seguir la educación. superior, es la realización de la formación integral. La nueva variedad de necesidades sociales y por consiguiente de profesiones y la gran diversificación de la tarea científica necesaria si quiere avanzar en profundidad y perfeccionar los conocimientos que nos lega el patrimonio cultural adquirido, hace correr al hombre los riesgos de la atomización del saber, la nivelación destructora de los conocimientos y convertir a las instituciones de cultura superior en factor de desintegración cultural y a la ciencia en frase de Zubiri, en secreción de verdadesi. En todo universitario, la institución debe favorecer y dar los medios para que al mismo tiempo que se especializan para los cometidos específicos y cualificados, no se pierda de vista al hombre en su sentido y significación integral. Ni la diversificación de las carreras universitarias ni la clásica bipolaridad entre ciencias y letras, debe inducir a una ignorancia mutua. El científico debe justificar su tarea y encontrarle sentido, dentro del más amplio horizonte en el que se definen os valores humanos y en el que todo saber confluye en la enorme labor colectiva de ir creando dentro de la evolución histórica: el esfuerzo porque la expresión del hombre en el mundo se armonice cada vez más con la medida y calidad de sua propia dignidad humana. Puede pensarse que nuestra Universidad necesita medidas eficaces en la programación que favorezcan tal integración cultural para evitar que el hombre especializado pueda ser sinónimo de hombre inculto. En este ambicioso programa de la reforma universitaria española debe huirse de los peligros igualmente graves: uno el 
confundir la educación universitaria con una educación generalizada de masas; otro el reducir la educación universitaria, con la profileración y atomización de centros en toda la geografía peninsular en una educación de contenido profesional.

Precisamente con la difusión de los medios técnicos de educación de masas y de la educación generalizada, han surgido voces de alarma que debem hacernos meditar. El sociólogo Eco ha expresado lo términos en que se desarrolla la tensión entre cultura general y cultura de masas: si la cutura es un hecho aristocrático, cultivo celoso asiduo y solitario de una interioridad refinada que se opone a la vulgaridad de la muchedumbre la nueva idea de una cultura compartida por todos, producida de modo que adapte a todos y elaborada a medida de todos, es un contrasentido monstruoso. La cultura de masas es anticultura. $Y$ puesto que esta nace en el momento en que la presencia de las masas en la vida social se convierte en el fenómeno más evidente de un contexto histórico, la cultura de masas no es signo de una aberración transitoria limitada, sino que llega a constituir el signo de una caida recuperable ante la cual el hombre de cultura no puede más que expresarse en términos de Apocalipsis. En esta visión apocalíptica de la cultura de masas se lamenta sobre todo la desaparición de la virtud, la ascética que es absolutamente necesaria para anteponerse un nivel cultural. La Universidad debe enseñar al hombre algo más alto que esta mera cultura de masas, de lo contrario como se ha dicho, el hombre de mañana, será una especie de inferior mental que oirá música funcional durante sus jornadas de trabajo y que en sus tiempos de ocio permanecerá frente al televisor permanentemente encendido en aptitud estática, inerte y pasiva. Vivimos en el predominio de la cultura de imagen, llamada también cultural de bolsillo, hasta el punto de que el predominio de la imagen se ha convertido en el quinto poder de la sociedad del siglo XX. Algunos autores como MacDonald, dice que entre a cultura de masas y la cultura superior es hoy definitiva, irreversible e inmediata. Si como sostiene MacLuhan somos esclavos inconscientes de los instrumentos de que no servimos, la cultura superior, el proceso a una propia mentalización a un pensamiento propio e integrador debe sacar al universitario de esta masa amorfa e igualitaria que amenaza con dar al traste con nuestra civilización.

Otro de los peligros que apuntábamos es de la excesiva preocupación por dar a la formación y educación universitaria un contenido pro- 
fesional. El utilitarismo de la vida presente y la extensión del ocio que el universitario sea un espiritu cada día más evadido al mismo tiempo que más atento para las concretas realizaciones utilitarias y pragmáticas. Por ello el día que la Universidad haya dejado de hacer ciencia - por la ciencia habrá perdido su primera y más sublime misión.

Permitidme que termine esta exposición con una visión esperanzadora del porvenir: el espíritu y la tradición de nuestras viejas y nuevas Universidades superará los temporales del presente como ha superado los vaivenes de la historia . 